\title{
Facile Amine Termination of Nanodiamond Particles and Their Surface Reaction Dynamics
}

\author{
Ashek-I-Ahmed, ${ }^{\dagger}$ Laia Gines, ${ }^{\ddagger}$ Soumen Mandal, ${ }^{\ddagger \odot}$ Chang-You Song, ${ }^{\dagger}$ Oliver A. Williams, ${ }^{\ddagger}$ \\ Micahella N. Sarmiento, ${ }^{\dagger}$ and Chia-Liang Cheng* ${ }^{\dagger} \dagger$ \\ ${ }^{\dagger}$ Department of Physics, National Dong Hwa University, Hualien 97401, Taiwan \\ ${ }^{\ddagger}$ School of Physics and Astronomy, Cardiff University, Cardiff CF24 3AA, U.K.
}

\section{Supporting Information}

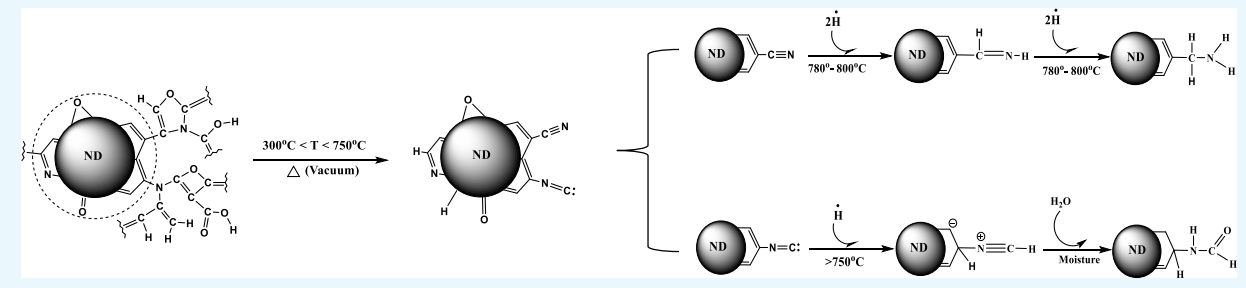

ABSTRACT: Nanodiamond synthesized by the detonation method is a composite of $\mathrm{sp}^{3} / \mathrm{sp}^{2}$ carbon structures; amorphous and disordered- $\mathrm{sp}^{2}$ carbons populate the surface of a $\mathrm{sp}^{3}$ diamond core lattice. Because of the production process, various

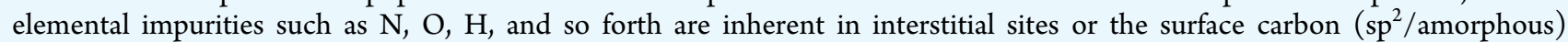
network. Herein, the reaction dynamics on the surface of ultradisperse diamond (UDD) due to the surface transformation or reconstruction during annealing in vacuum with temperatures ranging from ambient to $800{ }^{\circ} \mathrm{C}$ is described. In situ measurement of Fourier transform infrared spectroscopic analysis shows that low-temperature $\left(<500{ }^{\circ} \mathrm{C}\right)$ annealing of UDD in vacuum results in isonitrile/isocyanide $(-\mathrm{N}=\mathrm{C}:)$ and nitrile functionalization $(-\mathrm{C} \equiv \mathrm{N})$ on the surface. At temperatures $\sim 500$ ${ }^{\circ} \mathrm{C}$, the surface hydrogenation of UDD is initiated. During annealing at $780-800{ }^{\circ} \mathrm{C}$, the nitrile group $(-\mathrm{C} \equiv \mathrm{N})$ is reduced to the primary amine $\left(\mathrm{NH}_{2}\right)$, and isonitrile $(-\mathrm{N}=\mathrm{C}:)$ turns it to be in the saturated (Aryl/R- $\left.\stackrel{\oplus}{\mathrm{N}} \equiv \mathrm{C}-\mathrm{H}\right)$ structure. On exposure to air, the obtained isonitrile is transformed to an $\mathrm{N}$-formyl derivative (Aryl/R-NH-CHO) structure via hydrolysis. This study provides a fundamental insight into the surface reactive profile of UDD which could lead to facile surface functionalization properties and their applications in various fields such as biomedical, biosensing, drug delivery, epoxy materials process, tribology, and possibly in cyano $(-\mathrm{C} \equiv \mathrm{N} /-\mathrm{N}=\mathrm{C}:)$ chemistry.

\section{INTRODUCTION}

Nanodiamonds (NDs) are a promising material in the carbon family with numerous applications at the interface of biology, medicine, and physical science. Super hardness, high thermal conductivity, and chemical resistance make them useful in cutting, polishing, material coatings, and cooling additives in lubricants. ${ }^{1}$ At the same time, visibly excited color centers (such as the $\mathrm{NV}^{-} \approx 637 \mathrm{~nm}, \mathrm{NV}^{\circ} \approx 575 \mathrm{~nm}$ ) with stable luminescence, phonon vibrational signature $\left(1332 \mathrm{~cm}^{-1}\right)$, tailorable surface, and innate biocompatibility make NDs a unique tool in photonics and bio/medical applications, for example, in biosensing, biolabeling, imaging, and drug delivery, and so forth. ${ }^{1,2}$ With various novel properties, NDs, however, exhibit some major drawbacks, such as aggregation/clustering and inhomogeneous surface-chemical reactivity because of their complex surface structure. ${ }^{3,4}$ The observed surface complexity is widely considered to be driven by the nondiamond carbon fragments $\left(\mathrm{sp}^{2}\right.$; fullerene or graphene such as shells and amorphous) including various oxide groups which are inherently settled on the surface of the processed ND.,
The surface chemistry of ultradisperse diamond (UDD), also referred as detonation ND (DND), compared to other synthetic diamonds is still poorly understood. It is well known that due to the narrow size distribution and high surface area, UDD contains large amount of non-diamond carbons $\left(\mathrm{sp}^{2} /\right.$ amorphous) with several elemental contents such as $\mathrm{O}, \mathrm{N}, \mathrm{H}$, and so forth on the surface. ${ }^{1,3}$ Recently, it has been shown that annealing UDD in vacuum/gas phase yields catalytic activity. $^{7-9}$ Various studies suggested that the surface elemental bonding-rebonding and desorption processes during annealing which lead to the structural transformation or reconstruction of the surface non-diamond carbon structures are the key factors of the surface reactivity of UDD. $^{7,8,10}$ Thus, the analysis of surface signatures during vacuum annealing/post-treatment of UDD is crucial to uncover their reactive profile.

Received: March 21, 2019

Accepted: September 19, 2019 
In general, the reduction/hydrogenation of nitrile or isonitrile occurs in the presence of metal ( $\mathrm{Pt}, \mathrm{Pd}, \mathrm{Ni}$, etc.)/ metal free catalysts. ${ }^{11-13}$ It is assumed that the reduction of the cyano-group $(-\mathrm{C} \equiv \mathrm{N} /-\mathrm{N}=\mathrm{C}$ :) formed by annealing on the surface of UDD could be activated by the influence of high temperature in the presence of atomic/radical hydrogen. The origin of atomic/radical hydrogen is the effect of hydrogen molecule $\left(\mathrm{H}_{2}\right.$, abundant in all vacuum chambers) dissociation activated by the annealing of UDD at low temperatures $(\sim 500$ $\left.{ }^{\circ} \mathrm{C}\right) .8,14$

The surface modification with suitable linkers is a required process to utilize ND for further applications. Over several processes, hydrogen treatment is considered to be substantially effective to stabilize the diamond surface for further chemical terminations. Functionalization of NDs with amino groups $\left(\mathrm{N}-\mathrm{H} / \mathrm{NH}_{2}\right)$ is viable as a platform of conjugating larger moieties such as drugs, proteins, genes, molecular compounds, and so forth. ${ }^{15,16}$ Besides, amino-functionalized ND is widely applied to enhance the hardness of epoxy resins ${ }^{17-19}$ which are used in various fields, such as aerospace, navigation, anticorrosion, and so forth. ${ }^{20}$ It also has significant potential in solid-state peptide synthesis and as a solid support in chromatography/separation science. ${ }^{17,21}$

In this work, in situ measurement of Fourier transform infrared (FTIR) spectroscopic analysis of UDD annealed in vacuum at the range of room temperature to $800{ }^{\circ} \mathrm{C}$ is described. At each annealing step and temperature, in situ IR spectra were obtained and analyzed. It was found at low temperature $\sim 300{ }^{\circ} \mathrm{C}$, annealing of UDD enables the surface nitrogen to be rearranged as isonitrile $(-\mathrm{N}=\mathrm{C}:)$ and nitrile $(-\mathrm{C} \equiv \mathrm{N})$ bonding and the surface hydrogenation to start, the $\mathrm{C}-\mathrm{H}$ functionalization is found to be initialized at $\sim 500{ }^{\circ} \mathrm{C}$ in this study, depending on the availability of the hydrogen in the chamber. With further annealing, the obtained isonitrile $(-\mathrm{N}=\mathrm{C})$ and nitrile $(-\mathrm{C} \equiv \mathrm{N})$ are reduced by the radical hydrogen at higher temperature $\left(780-800{ }^{\circ} \mathrm{C}\right)$ which leads to a multifunctional surface of UDD with amine $\left(\mathrm{N}-\mathrm{H} / \mathrm{N}-\mathrm{H}_{2}\right)$ / $\mathrm{N}$-formyl derivative $(-\mathrm{NH}-\mathrm{CHO})$. The observed results reveal that the surface chemistry of UDD could be dependent on the desorption, reconstructions, or structural transformations of the non-diamond carbons.

\section{MATERIALS AND METHODS}

Synthetic ultradispersed diamond (UDD) particles of grain size 4-5 nm were sourced from PlasmaChem $\mathrm{GmbH}$, Germany (Grade G01). These particles contain metal contaminants such as $\mathrm{Fe}, \mathrm{Cu}, \mathrm{Zn}, \mathrm{Mn}$, and so forth, with negligible percentages [see the Supporting Information]. Powder of $50 \mathrm{~nm}$ diamonds was purchased from Microdiamant, Switzerland. For FTIR measurements, samples of ND with concentration of $2 \mathrm{mg} / 60 \mathrm{~mL}$ were dispersed in deionized water and drop-cast onto Si substrates with $20 \mathrm{~mL}$ of solution. They were then dried in the desiccator for $24 \mathrm{~h}$. To obtain larger volumes of specimen, drop-casting was repeated two/ three times over the previous layer. A sample holder was prepared using tantalum foil and wire to secure the $\mathrm{Si}$ substrate. The samples were placed in a UHV chamber directly in the path of the infrared beam of the FTIR apparatus. All IR measurements were performed in situ at room temperature after the samples had been subjected to various temperature annealing steps, at a chamber base pressure of $\sim 2 \times 10^{-7}$ Torr. The spectra were collected using Bomem MB154 FTIR equipped with an MCT-liquid nitrogen-cooled detector. The resolution was set to be $4 \mathrm{~cm}^{-1}$, and 400 scans were used. Ambient humidity around the FTIR was $\sim 38-40 \%$. X-ray photoelectron spectroscopic (XPS) data were collected using Thermo Scientific Al-K-Alpha X-ray Photoelectron Spectrometer at the $\sim 3 \times 10^{-9}$ Torr vacuum level. The fitting of XPS spectra was calculated using the Thermo Scientific software package. Raman spectra were recorded using a JY T6400 spectrometer with $325 \mathrm{~nm}$ wavelength of laser excitation of $\sim 0.4 \mathrm{~mW}$ power, accusation time $\sim 30 \mathrm{~s}$.

\section{RESULTS AND DISCUSSION}

Figure $1 \mathrm{a}(\mathrm{i})$ shows the FTIR spectrum of untreated UDD. A broad band around the range of $1000-1250 \mathrm{~cm}^{-1}$ is well

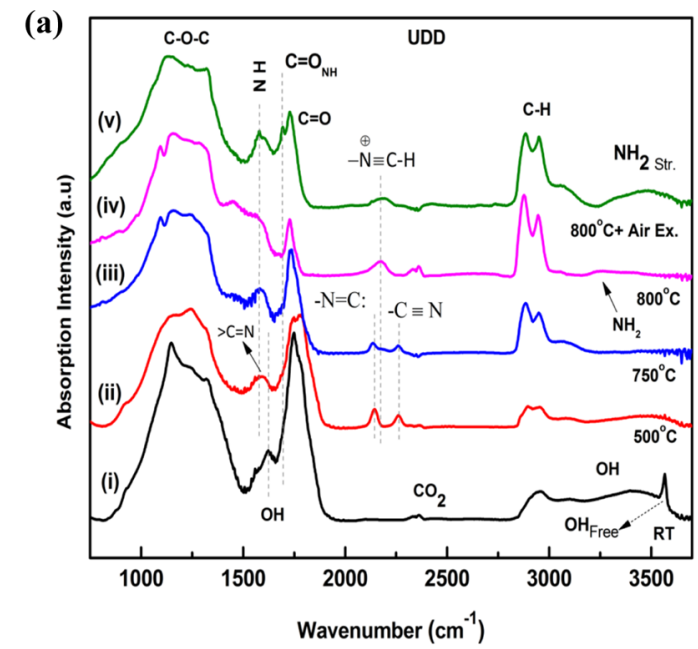

(b)

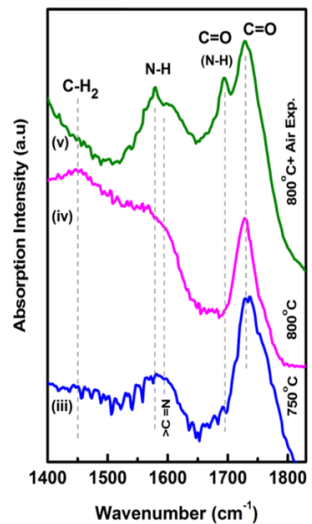

(c)

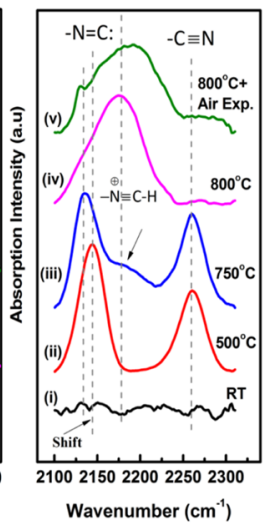

(d)

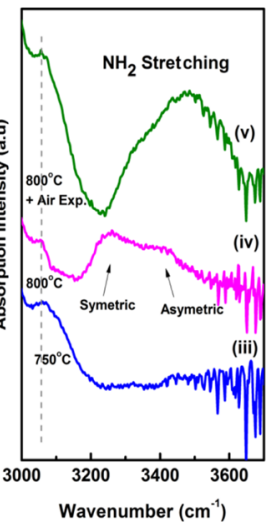

Figure 1. FTIR spectra of untreated and surface-treated UDD measured in situ; (a) (i) untreated UDD, (ii-iv) corresponds to the UDD annealed at various temperatures $\left(500,750\right.$, and $800{ }^{\circ} \mathrm{C}$ ) in vacuum (base pressure $\sim 2 \times 10^{-7}$ Torr), (v) sample (iv) exposed in air for $24 \mathrm{~h}$, (b) magnified spectral view of the samples (iii-v) in the range of $1400-1840 \mathrm{~cm}^{-1}$, (c) for the samples (i-v) in the range of 2050-2380 $\mathrm{cm}^{-1}$, and (d) for the samples (iii-v) in the range of $3000-3650 \mathrm{~cm}^{-1}$.

known for the cyclic ether/ester groups $\mathrm{C}-\mathrm{O}-\mathrm{C} / \mathrm{C}-\mathrm{O}$ on $\mathrm{ND}$. The $\mathrm{C}=\mathrm{O}$ peak attributed to the carboxylic acid $(-\mathrm{COOH}) /$ ketone $(\mathrm{R}-\mathrm{CO}-\mathrm{R}) /$ acid anhydride group is observed at the range $1650-1800 \mathrm{~cm}^{-1}$. Features with the broad bands at $1620-1640$ and $3400-3600 \mathrm{~cm}^{-1}$ correspond to hydroxyl group $\mathrm{OH}$, originated from the surface-adsorbed water/COOH groups. ${ }^{22}$ The atmospheric $\mathrm{CO}_{2}$ is identified in 
Scheme 1. (a) Untreated UDD with Possible Surface Groups (Schematically Displayed), a Part of the Upper Layer is out of the Circle; (b) Modified Surface after Annealing in the Range $300{ }^{\circ} \mathrm{C}<T<750{ }^{\circ} \mathrm{C}$

(a)

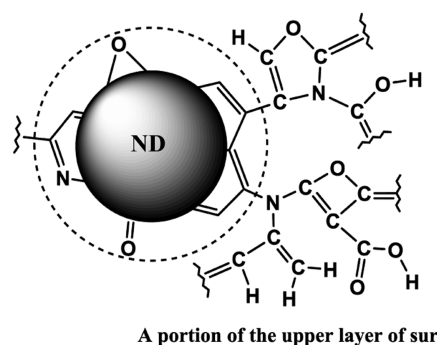
(outside the circle) (b)

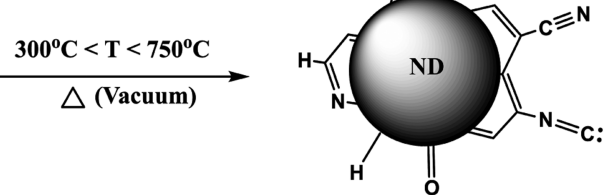

Surface after annealing $300^{\circ} \mathrm{C}<\mathrm{T}<750^{\circ} \mathrm{C}$

the range of $2350-2400 \mathrm{~cm}^{-1}$. The $\mathrm{C}-\mathrm{H}$ stretching feature from various origins is visible at the range of $2800-3000$ $\mathrm{cm}^{-1} .23$

After annealing UDD at temperatures nearly $300{ }^{\circ} \mathrm{C}$ (figure shows at $500{ }^{\circ} \mathrm{C},<500{ }^{\circ} \mathrm{C}$ is presented in the Supporting Information) in vacuum, two distinct peaks shown in Figure la(ii) appear at $\sim 2143$ and $\sim 2259 \mathrm{~cm}^{-1}$ which are attributed to the iso-nitrile/isocyanide $(-\mathrm{N}=\mathrm{C}$ : $)$ with conjugated structures and nitrile $(-\mathrm{C} \equiv \mathrm{N})$ groups, respectively. ${ }^{22,24} \mathrm{~A}$ slightly broadened band assigned for the $\mathrm{C}=\mathrm{N}$ stretching vibration or $\mathrm{N}$-incorporated $\mathrm{C}=\mathrm{C}(-\mathrm{N}=\mathrm{C}=\mathrm{C}<)$ bond in a graphitic ring/carbon chain is observed at $1595 \mathrm{~cm}^{-1} \cdot 22,25$ This band is defined as the characteristic band of the isonitrile $(-\mathrm{N}=\mathrm{C}:)^{22}$ It is noted that as the $\mathrm{OH}$ group corresponds to a broad band in the range $1620-1640 \mathrm{~cm}^{-1}$, the IR peak of the $\mathrm{C}=\mathrm{N}$ structure could be overlapped at the room temperature as shown in Figure $1 \mathrm{a}(\mathrm{i})$.

It has been studied that the DND contains elemental nitrogen $(\mathrm{N})$ as most abundant impurities which can be present in the interstitial and surface carbon structure. ${ }^{26}$ The FTIR spectrum of the observed carbon-nitrogen bonding known as the cyano-group strongly indicates that UDD contains a considerable amount of nitrogen at the surface which is bonded in the surface carbon network. In the previous study, it has been shown that annealing UDD at low temperature $\left(<500{ }^{\circ} \mathrm{C}\right)$ results in the desorption of surface carbon as a radical form. ${ }^{8}$ Therefore, it is assumed that during the desorption of surface carbon as well as other molecular groups, the surface nitrogen could be rearranged with a form of $\mathrm{sp} / \mathrm{sp}^{2}$ carbon-nitrogen bonding as shown in Scheme 1 . The probable configuration of the nitrile and isonitrile, in general, is expected at the terminus of a graphitic ring or linear carbon chain. It is noted that the similar characteristic bond is commonly observed during the carbon-nitride $(\mathrm{CN})$ thin-film deposition. ${ }^{25,27}$ It is well known that nitrile and isonitrile have two resonant structures as shown below

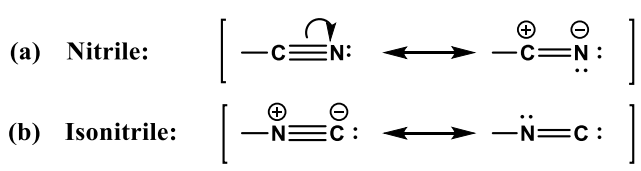

The electronic structure analysis of isonitriles using highlevel valence bond calculations suggests that isonitriles are better described as carbenes than as zwitterionic structures. Moreover, the linearity of the carbene favors delocalization of the nitrogen lone pair leading energetic stabilization. ${ }^{28,29}$ Therefore, the possible structure of nitrile and isonitrile could be considered for our reaction study in their charge neutral state $(-\mathrm{C} \equiv \mathrm{N}$ : and $-\mathrm{N}=\mathrm{C}:)$. The density of these bonds could be influenced by the temperature of the medium as isonitrile $(-\mathrm{N}=\mathrm{C}:)$ could be transformed into the nitrile $(-\mathrm{C} \equiv \mathrm{N})$ structure or vice versa over $200{ }^{\circ} \mathrm{C} .{ }^{30,31}$

At $500{ }^{\circ} \mathrm{C}$, two distinct peaks at $2875-2945 \mathrm{~cm}^{-1}$ attributed to $\mathrm{C}-\mathrm{H}$ as shown in Figure $1 \mathrm{a}(\mathrm{ii})$ appeared. This $\mathrm{C}-\mathrm{H}$ feature suggests that the origin of $\mathrm{C}-\mathrm{H}$ bonding is from the dangling carbon of a tetrahedral diamond lattice, not from graphitic/ amorphous/polymeric hydrocarbons that are physically adsorbed on the ND surface. The physically adsorbed $\mathrm{CH}$ would have been desorbed at this temperature under vacuum. ${ }^{23}$ In addition, previously, the authors have shown that the hydrogenation of UDD can be derived by the radical dissociation of molecular hydrogen $\left(\mathrm{H}_{2}\right)$ during annealing of UDD at relatively low temperatures $\left(<500{ }^{\circ} \mathrm{C}\right) .{ }^{8,14}$ In this case, although there was no external source of $\mathrm{H}_{2}$, a similar effect could be obtained from the low concentrations of hydrogen molecules (background $\mathrm{H}_{2}$ ) present in all vacuum chambers; ${ }^{32,33}$ and this was also evidenced from the mass spectra of our previous result. ${ }^{8}$ At higher temperatures $\left(>550{ }^{\circ} \mathrm{C}\right)$, the dominant feature of $\mathrm{C}-\mathrm{H}$ adsorption confirms that the rate of $\mathrm{H}_{2}$ availability is higher at high temperature (observed from $>550{ }^{\circ} \mathrm{C}$ ) due to degassing, corresponding to a common phenomenon of the vacuum system from the stainless chamber walls. $^{32,33}$

At $800{ }^{\circ} \mathrm{C}$ (observed from $\sim 780{ }^{\circ} \mathrm{C}$ ), the peak assigned for the nitrile group $(-\mathrm{C} \equiv \mathrm{N})$ is completely disappeared as shown in Figure 1c(iv). At the same time, a distinct band in the range of 3200-3450 cm $\mathrm{cm}^{-1}$ shown in Figure $1 \mathrm{~d}(\mathrm{iv})$ is observed corresponding to the primary amine $\left(\mathrm{NH}_{2}\right)$ with symmetric and asymmetric stretch vibrations. ${ }^{34} \mathrm{~A}$ small peak at lower frequencies $\sim 1450 \mathrm{~cm}^{-1}$ assigned to the $\mathrm{C}-\mathrm{H}_{2}$ deformation vibration is also found as shown in Figure $1 b(i v){ }^{22}$ The formation of primary amine as well as $\mathrm{C}-\mathrm{H}_{2}$ groups indicates that the nitrile group has been reduced/hydrogenated by annealing at $800{ }^{\circ} \mathrm{C}$ which leaves the alkyl-conjugated amine structure $\left(-\mathrm{CH}_{2}-\mathrm{NH}_{2}\right)$ on the surface of UDD. In general, hydrogenation/reduction of nitrile occurs in the presence of metal-catalysts such as $\mathrm{Ni}, \mathrm{Pt}, \mathrm{Ru}$, and so forth. ${ }^{11,12}$ It has been found that in the gas phase, atomic hydrogen does not react with nitrogen atoms at temperatures lower than $350{ }^{\circ} \mathrm{C}$; even over $350{ }^{\circ} \mathrm{C}$, the reaction efficiency is negligible. ${ }^{35}$ In contrast, $\mathrm{Li}$ and $\mathrm{Tan}$ have shown that atomic/radical hydrogen can interact with nitrogen at temperatures over $700{ }^{\circ} \mathrm{C}$, which leads to the direct hydrogenation of the carbon-nitride structure. ${ }^{36} \mathrm{We}$ assume that high-temperature $\left(780-800{ }^{\circ} \mathrm{C}\right.$ ) annealing of UDD could provide enough surface activation energy to stimulate the reduction of nitrile via adsorption of 
Scheme 2. Reaction Steps of the Formation of Primary Amine on the Surface via Multiple (Step1 \& 2) Reductions of the Nitrile Group During Annealing the UDD at $780-800{ }^{\circ} \mathrm{C}$ in Vacuum

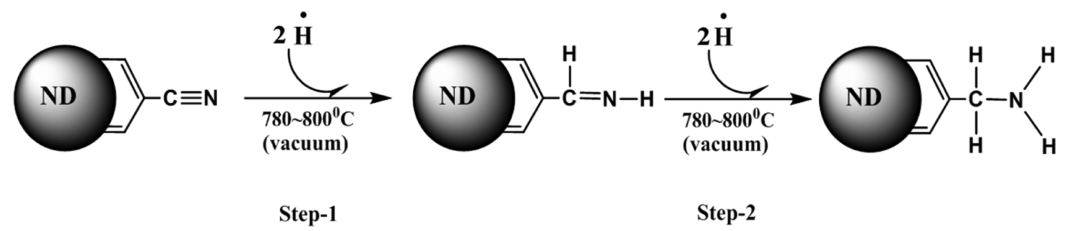

Scheme 3. (i) Reaction Steps of Isonitrile for the Transformation of Unsaturated to Saturated Structures; Steps (1-2) Describes the Possible Resonance State of Isonitrile during Annealing of UDD, Step 3 is the Stage of Hydrogen Radical Adsorption to the Terminal Carbon of Isonitrile, Step (4-5) Shows Radical Stabilization in the Carbon-Nitrogen Chain before the Next Hydrogen Attack, Step 6 is the Possible Stage of Radical Neutralization in the Chain via Hydrogen Adsorption Corresponding to a Saturated Structure of Isonitrile; (ii) Hydrolysis of Isonitrile under Air Exposition, Resulting in the Formation of the $N$-formyl Derivative Structure (Steps 1-2)

(i)
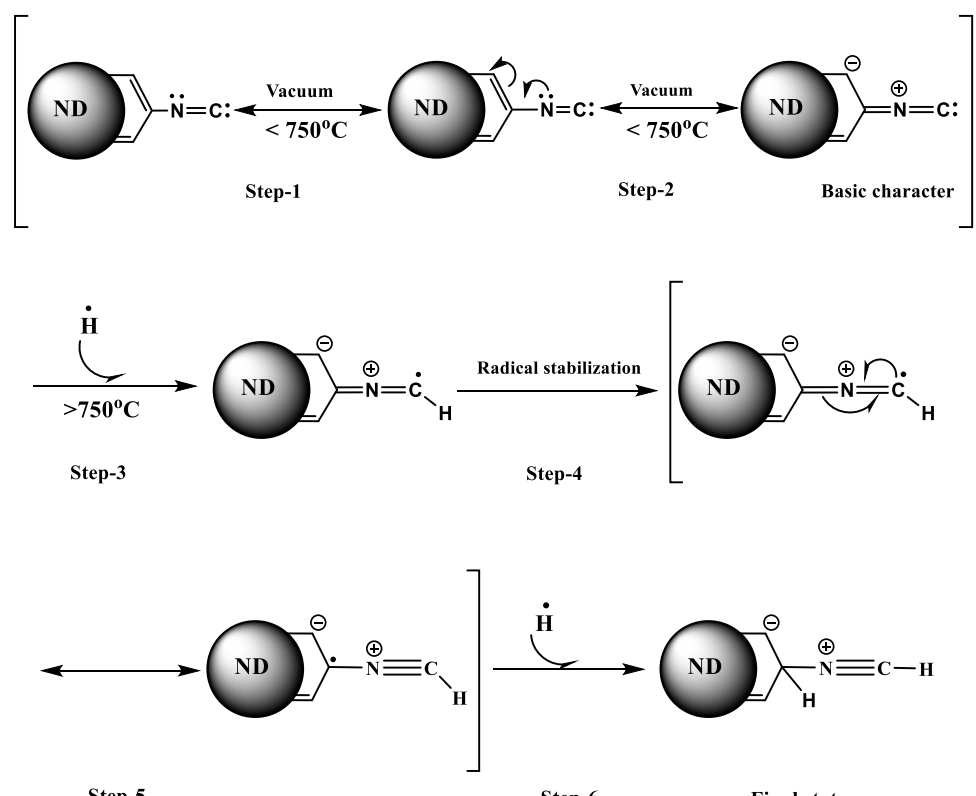

Step-5

Step-6

Final state

(ii)

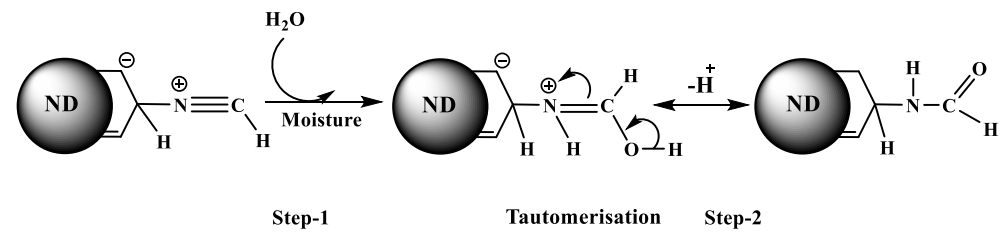

radical hydrogen in the reaction chamber. ${ }^{8}$ The reaction mechanism of nitrile reduction proposed is displayed in Scheme 2. It is noted that for alkyl-amine $\left(-\mathrm{CH}_{2}-\mathrm{NH}_{2}\right)$, a stretching band of $\mathrm{C}-\mathrm{H}$ with medium intensity is expected at the region of $2850-2945 \mathrm{~cm}^{-1}$. However, as the $\mathrm{C}-\mathrm{H}$ peak on diamond surfaces carries the dominant character at the same frequency range, therefore, $\mathrm{C}-\mathrm{H}$ for the alkyl structure could be overlapped with the diamond feature.

In the case of isonitrile, the IR peak at $\sim 2143 \mathrm{~cm}^{-1}$ corresponds to its conjugated/unsaturated ( $\equiv \mathrm{C}-\mathrm{N}=\mathrm{C}: /=$ $\mathrm{C}-\mathrm{N}=\mathrm{C}:$ ) structure, ${ }^{22}$ the most probable conjugated structure in our sample is expected with graphitic rings as shown in Scheme 1. At a temperature of $750{ }^{\circ} \mathrm{C}$, the peak is slightly shifted toward the down frequency at $2137 \mathrm{~cm}^{-1}$. At the same time, a new peak is raised around $\sim 2175 \mathrm{~cm}^{-1}$, which corresponds to an unconjugated/saturated form of isonitrile, as shown in Figure 1c(iii) (marked by arrow). ${ }^{22}$ It has been well studied that isonitrile/isocyanide exhibits relatively higher basicity than nitrile in reaction medium, especially in the gas phase $^{37,38}$ Because of this basicity, it is expected that during annealing of UDD, the nitrogen atom in isonitrile (Scheme $1 \mathrm{~b}$ ) could donate a lone-pair electron to the adjacent graphitic ring as can be seen in conjugated/aryl-amine. ${ }^{39}$ It has also been found that isonitrile/isocynaide in a conjugated structure ( $\mathrm{R}-$ $\mathrm{N}=\mathrm{C}$ : or $\operatorname{Aryl}-\mathrm{N}=\mathrm{C}$ ) can act as a radical acceptor. ${ }^{40,41}$ Therefore, the observed frequency shifting from 2143 to 2137 $\mathrm{cm}^{-1}$ could be a simultaneous effect of the hydrogen radical attack as well as the structural transformation of isonitrile due to basicity. The possible result of the reaction is shown in Scheme 3(i); steps $(1-3)$. 
As a result of hydrogen termination in step 3, an unpaired electron/free radical is created at the terminated carbon of the isonitrile which is transferred immediately to the ring structure because of its stabilization via a resonance stage as shown in steps (4-5). ${ }^{42,43}$ The obtained radical could finally be neutralized by termination with successive hydrogen radicals as shown in step 6. As a result, the isonitrile is transformed to an unconjugated or saturated structure corresponding to the IR peak at $2175 \mathrm{~cm}^{-1}$. The small intensity of the peak indicates that the kinetic energy of the reaction might not be enough to provide a large amount of product at $750{ }^{\circ} \mathrm{C}$. At higher temperature $\left(780-800{ }^{\circ} \mathrm{C}\right)$, the reaction is completely observed, leading a distinguished IR feature of saturated isonitrile at $2175 \mathrm{~cm}^{-1}$ as shown in Figure $1 \mathrm{c}(\mathrm{iv})$.

On exposure to the air/moisture of the sample after annealed at $800{ }^{\circ} \mathrm{C}$, a distinguished side band at $1694 \mathrm{~cm}^{-1}$ corresponding to the $\mathrm{C}=\mathrm{O}$ bond in a conjugated amine structure $(-\mathrm{NH}-\mathrm{CO}-)$ is observed as shown in Figure $1 \mathrm{~b}(\mathrm{v}) .^{22,44}$ A sharp peak is also observed at $1577 \mathrm{~cm}^{-1}$ which could be related to $\mathrm{N}-\mathrm{H}$ deformation. ${ }^{22,45}$ We assume that during the sample exposure/transfer to the ambient (from vacuum after annealing at $800{ }^{\circ} \mathrm{C}$ ), the obtained structure of isonitrile is shown in Scheme 3(i); step 6 could be hydrolyzed and transformed to the $\mathrm{N}$-formyl derivative (Aryl/R-HN$\mathrm{CO}-\mathrm{H})$ structure by tautomerization. ${ }^{46,47}$ The reaction steps are displayed in Scheme 3(ii); step (1-2). Note that after tautomerization, the remaining negative charge at the ring structure could be neutralized by the released proton $\left(-\mathrm{H}^{+}\right)$. In the FTIR spectrum, the effect of $\mathrm{N}-\mathrm{H}$ stretching vibration $\left(3300-3500 \mathrm{~cm}^{-1}\right)$ is not very obvious. The reason for this could be the result of frequency overlapping with primary amine $\left(\mathrm{NH}_{2}\right)$ /adsorbed-OH which lead to a broad band around $\sim 3200-3600 \mathrm{~cm}^{-1}$ as shown in Figure $1 \mathrm{~d}(\mathrm{iv})$. It is also noted that after the air exposition, the remaining peak of isonitrile at $2175 \mathrm{~cm}^{-1}$ as shown in Figure $1 \mathrm{a}(\mathrm{v})$ could be the effect of unsaturated/lack of hydrolysis in the duration.

The obtained $N$-formyl derivative was stable at room temperature. It should be noted that after the amide stage (-HN-CO-), further hydrolysis cannot be possible as the reaction steps require a catalyst such as strong acid $\left(\mathrm{H}_{2} \mathrm{SO}_{4}\right)$ or strong base $(\mathrm{NaOH})$ with specific temperature conditions. ${ }^{46,48}$ For the confirmation of the air effect, after annealing of UDD at $800{ }^{\circ} \mathrm{C}$, the sample was kept in vacuum overnight; no trace of the amide structure was found. This indicates that all of the reactions occurred inside the chamber have taken place via radical reaction, not by the influence of protonation/ ionization.

Figure 2 shows the XPS analysis of UDD. In Figure 2a, the comparative analysis of the $\mathrm{C} 1 \mathrm{~s}$ band for the untreated (i) and (ii) treated UDD at $800{ }^{\circ} \mathrm{C}$ (Vac. $\sim 2 \times 10^{-7}$ Torr) followed by air exposition for $24 \mathrm{~h}$ is shown. For the untreated UDD, deconvoluted fitting shows that the $\mathrm{C} 1 \mathrm{~s}$ spectrum corresponds to the presence of $\mathrm{sp}^{2}(\sim 284.8 \mathrm{eV}), \mathrm{sp}^{3}(\sim 286.3 \mathrm{eV})$ hybridized carbon, and their oxide groups such as $\mathrm{C}-\mathrm{O} /$ $\mathrm{C}=\mathrm{O} / \mathrm{COOH}(\sim 287-288 \mathrm{eV}){ }^{49,50}$ This oxide region in $\mathrm{C} 1 \mathrm{~s}$ is sometimes attributed to the $\mathrm{C}-\mathrm{N}$ energy band for nitrogendoped carbon structures; however, it has been ignored in our analysis due to the presence of the high-level oxygen signal. ${ }^{51}$

In the case of treated samples, a significant reduction of the $\mathrm{sp}^{2}$ carbon feature is observed as shown in Figure $2 \mathrm{a}(\mathrm{i}, \mathrm{ii})$. A parallel ratio of the reduction of oxide functional groups is also obvious which indicates desorption of non-diamond carbon fragments present on the surface of UDD. The maximum (a)

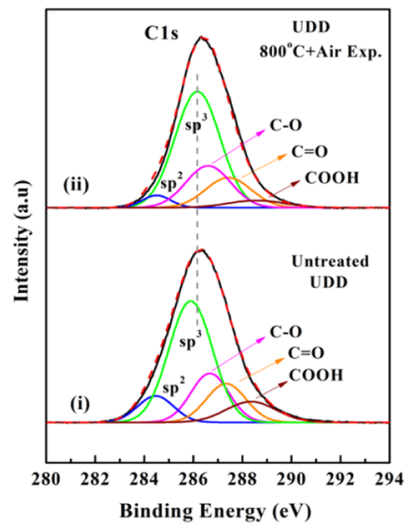

(c)

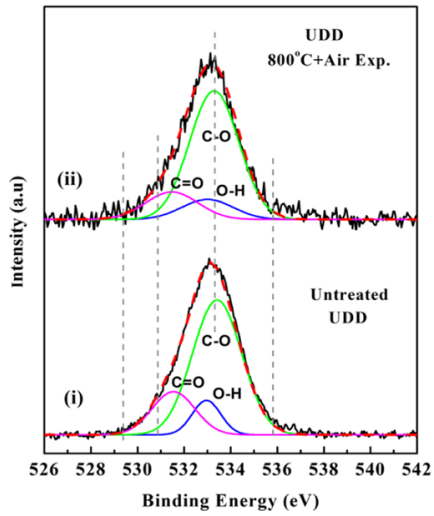

(b)

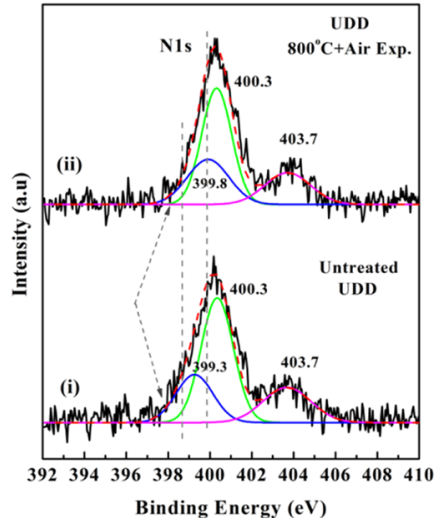

(d)

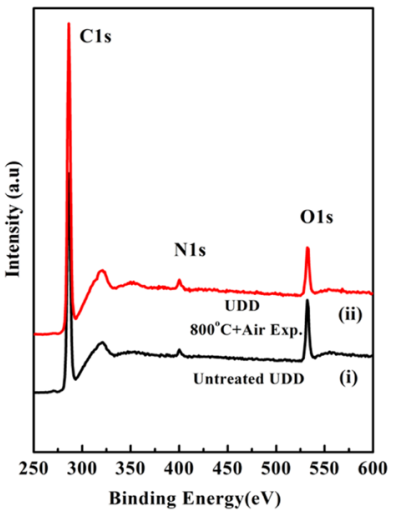

Figure 2. Comparative XPS analysis of (a) C 1s, (b) N 1s, and (c) O 1s for untreated UDD (i,ii) annealed at $800{ }^{\circ} \mathrm{C}$ followed by air exposition for $24 \mathrm{~h}$; (d) survey spectrum of the corresponding samples in the region of $\mathrm{C} 1 \mathrm{~s}, \mathrm{~N} 1 \mathrm{~s}$, and $\mathrm{O} 1 \mathrm{~s}$.

elimination of $\mathrm{C}=\mathrm{O}$ groups corresponding to the acidic group is observed. In contrast, the $\mathrm{C}-\mathrm{O}$ bonding is found more stable at high temperature in both cases. The possible reason of their higher stability could be due to the $\mathrm{C}-\mathrm{O}-\mathrm{C}$ cyclic bonding on the surface of ND. ${ }^{52}$ The obtained results are quite consistent with the FTIR feature. As compared to the untreated sample, the full width at half-maximum (fwhm) of the $\mathrm{C} 1 \mathrm{~s}$ spectrum is reduced by $0.35 \mathrm{eV}$ for the treated one. It can be assumed that this spectral narrowing could be due to desorption of amorphous/ $\mathrm{sp}^{2}$ contents with oxide groups (dotted line with arrow marked), enhancing the surface area of the particle with a higher atomic percentage of $\mathrm{sp}^{3}$ core structures. After annealing, a shifting of the $\mathrm{sp}^{3}$ carbon band is also observed which indicates surface hydrogen $(\mathrm{C}-\mathrm{H})$ adsorption on diamond. ${ }^{49,53}$

Figure $2 \mathrm{~b}$ shows the corresponding analysis of the $\mathrm{N} 1 \mathrm{~s}$ energy band. Three deconvoluted curves have been fitted in our analysis. For untreated UDD, the peak at $399.3 \mathrm{eV}$ refers to the $\mathrm{sp}^{3}$-hybridized nitrogen-C/carbon-nitrogen covalent bonding $(-\mathrm{N}<)$ as can be seen in Scheme $1 \mathrm{a} .{ }^{50}$ The band with a peak at $400.3 \mathrm{eV}$ corresponds to the $\mathrm{sp}^{2} \mathrm{~N}-\mathrm{C}$ (399.6$400.3 \mathrm{eV}$ )-bonded structure in the surface graphitic layer of UDD, related to $\mathrm{C}=\mathrm{N}$ bonds observed in FTIR (1595 $\left.\mathrm{cm}^{-1}\right) .{ }^{54}$ A side band corresponding to the oxidized nitrogen structure is observed at $403.7 \mathrm{eV}^{51}$ After the sample is annealed, a major spectral shift of $399.3-399.8 \mathrm{eV}$ was observed. This shift is related to the formation of the amine/ 
amide $\left(\mathrm{N}-\mathrm{H}\right.$ or $\left.\mathrm{NH}_{2}\right)$ bond on the surface of UDD, ${ }^{55,56}$ and this is also evidenced from the FTIR spectra [Figure $1 \mathrm{a}(\mathrm{v})$ ]. The relative intensity of the graphitic $\mathrm{C}=\mathrm{N}$ band $(400.3 \mathrm{eV})$ for the annealed sample is found to be decreased slightly. As UDD contains graphitic/fullerene/graphene-like fragments on its surface, the downward intensity of $400.3 \mathrm{eV}$ could be related to their deformation/desorption during annealing. The band related to the oxide group $(402.0-406.0 \mathrm{eV})$ is identified as sharper than the untreated one. This could be due to surface oxygen reduction as well as their rearrangement in an ordered structure. In this case, the fwhm of the $\mathrm{N} 1 \mathrm{~s}$ spectrum is reduced by $0.45 \mathrm{eV}$; the spectral narrowing in the range of 397-399 eV (marked by arrow) indicates the structural transformation of $\mathrm{C}-\mathrm{N}$ bonding. ${ }^{51}$ After annealing UDD, although the $\mathrm{sp}^{2}$ carbon concentration is reduced as compared to the untreated one (Figure 2a(ii)), the nitrogen (N) concentration remains almost unchanged as shown in Figure $2 b(i i)$. This result indicates that the distribution of most nitrogen contents is not in the outer layer of the surface carbon network, rather in the adjacent graphitic layer of the crystalline $\mathrm{sp}^{3}$ structure of UDD, which are stable at high temperatures.

Figure $2 \mathrm{c}$ shows a comparative analysis of the $\mathrm{O} 1 \mathrm{~s}$ spectrum with three deconvoluted curves that confirm the presence of $\mathrm{C}-\mathrm{O}(533.3 \mathrm{eV}), \mathrm{C}=\mathrm{O}(531.4 \mathrm{eV})$, and $\mathrm{O}-\mathrm{H}(532.9 \mathrm{eV})$ groups on both untreated and surface-treated UDD. ${ }^{57,58}$ Compared to the untreated sample [Figure $2 c(i)$ ], a relative reduction of $\mathrm{C}=\mathrm{O}$ and $\mathrm{O}-\mathrm{H}$ groups is observed for the treated one. However, the presence of $\mathrm{C}-\mathrm{O}$ groups remains almost unchanged. In general, $\mathrm{C}-\mathrm{O}$ groups on diamond surfaces are mostly found as cyclic ether, where oxygen is bonded with two dangling carbons $(\mathrm{C}-\mathrm{O}-\mathrm{C})$. Because of their bonding nature, $\mathrm{C}-\mathrm{O}$ groups could be more stable on diamond surfaces at high temperature. ${ }^{52}$ Figure $2 \mathrm{~d}(\mathrm{i}, \mathrm{ii})$ corresponds to the comparative survey analysis of untreated and treated UDD with the $\mathrm{C} 1 \mathrm{~s}, \mathrm{~N} 1 \mathrm{~s}$, and $\mathrm{O} 1 \mathrm{~s}$ spectral region.

Figure 3(i,ii) shows the Raman spectra of untreated and treated UDD in the range of $1000-2000 \mathrm{~cm}^{-1}$. UV laser with

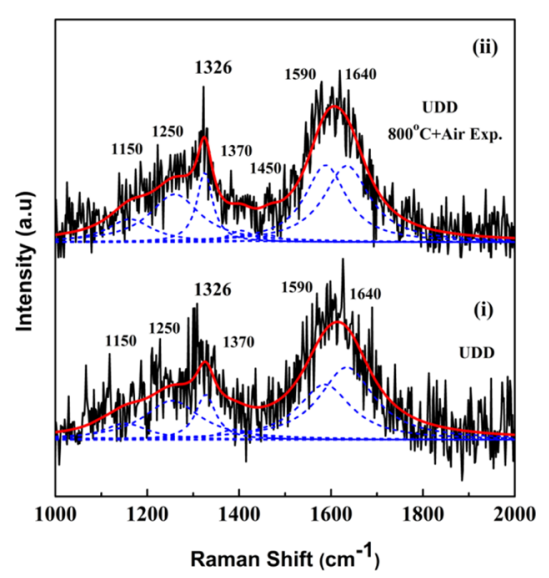

Figure 3. Raman spectra of UDD (i) untreated UDD and (ii) annealed UDD at $800{ }^{\circ} \mathrm{C}$ in vacuum and then exposed in air for $24 \mathrm{~h}$.

$325 \mathrm{~nm}$ excitation wavelength was used to induce higher $\mathrm{sp}^{3}$ scattering/suppress the D-band as well as avoiding the visibleluminescence associated with amorphous $/ \mathrm{sp}^{2}$ carbon which leads the spectral overlapping with the diamond signal. ${ }^{59,60}$ In Figure 3(i), on the UDD spectrum, a broad band between 1100 and $1400 \mathrm{~cm}^{-1}$ is expressed. The deconvoluted feature shows that the band is composed of trans-polyacetylene at $1150 \mathrm{~cm}^{-1}$ shouldered with amorphous carbon at $1250 \mathrm{~cm}^{-1}$, the first-order $\mathrm{sp}^{3}$-diamond mode at $1326 \mathrm{~cm}^{-1}$, and the disordered (D-band) carbon band in the range of 1370-1400 $\mathrm{cm}^{-1} .^{59,60}$ The down-shifting of the characteristic diamond peak compared to bulk diamond $\left(1332 \mathrm{~cm}^{-1}\right)$ is due to the phonon confinement effect observed in narrow-sized $(<10 \mathrm{~nm})$ crystal structures. $^{61}$ The well-known G-band related to the graphitic structure on diamond is observed in the range of $1540-1650 \mathrm{~cm}^{-1}$. As the size of UDD is very small and the surface contains large fraction of $\mathrm{sp}^{2}$ or amorphous carbons, the exposed radiation by laser in ambient can be absorbed and produce heat on the focal point which can burn the sample surface. Because of the burning effect, the spectrum of UDD can be undefined, resulting in the low signal to noise ratio as observed. Therefore, in the case of Raman spectral measurement of UDD, very small power $(\sim 0.5 \mathrm{~mW})$ is used which provides a higher signal to noise ratio.

The deconvoluted G-band suggests the presence of the $\mathrm{C}=$ $\mathrm{C}$ bond in fullerene/graphene shell-like fragments with the peak position at $1590 \mathrm{~cm}^{-1}$ and $\mathrm{O}-\mathrm{H}$ bonded structures on the corresponding $\mathrm{sp}^{2}$ carbon site at $1640 \mathrm{~cm}^{-1} .^{62}$ Over 1650 $\mathrm{cm}^{-1}$ is generally attributed to $\mathrm{C}=\mathrm{O}$ surface groups which are not significant in our sample spectrum. ${ }^{62}$ In contrast, the diamond signal for the treated UDD is found intensified and more obvious. This result indicates the decay/desorption of $\mathrm{sp}^{2}$ fragments/amorphous phase from the surface of the treated particles as $\mathrm{sp}^{2}$ exhibit higher Raman scattering cross-section than $\mathrm{sp}^{3}$ which leads to an overshadowed diamond signal for untreated UDD. ${ }^{63}$ A distinguished D-band with reduced intensity at $1400 \mathrm{~cm}^{-1}$ is observed. The broadened shape of the D-band shouldered with the diamond signal relates to the higher disorder on UDD than treated one. In addition, it also provides an understanding of structural reconstruction or transformation of the surface carbon network during annealing and possible carbon desorption which leads to elemental (C, $\mathrm{N}$, and $\mathrm{O}$ ) rebonding in the surface matrix. A consistent result is also obvious in G-band analysis; comparative signal intensity attributed to graphene/fullerene shell-like carbon $\left(1590 \mathrm{~cm}^{-1}\right)$ is enhanced in the treated UDD. As the most shell-like carbon structures are defined on the adjacent layer of the $\mathrm{sp}^{3}$-diamond core, ${ }^{1,63}$ the increased intensity of $1590 \mathrm{~cm}^{-1}$ indicates the desorption of outer layer carbon fragments (amorphous $/ \mathrm{sp}^{2}$ ) as well as the bonding and rebonding of surface elements that transforms the surface structure into an ordered shape. From the analysis of the G-band, it can be suggested that there is no substantial graphitization effect on the sample during annealing at $800{ }^{\circ} \mathrm{C}$, which is consistent with literature reports. ${ }^{7,64} \mathrm{~A}$ small band at $1450 \mathrm{~cm}^{-1}$ is slightly distinguished but not very obvious which might be the result of transpolyacetylene. ${ }^{59}$ The oxygen level related to the $\mathrm{O}-\mathrm{H}$ group $\left(1640 \mathrm{~cm}^{-1}\right)$ on the surface is relatively reduced by post treatment. These findings in Raman measurement are consistent with the results of XPS and FTIR.

From the abovementioned observations, it is obvious that annealing UDD could result in desorption of surface elemental contents such as carbon, oxygen, and their bonding nature $(\pi$ or $\sigma$ ) which leads to the transformation/reconstruction of the surface. It was found that these phenomena are mostly derived by the amorphous $/ \mathrm{sp}^{2}$ carbons present on the surface of UDD; therefore, the obtained results were not effective on larger size $(>10 \mathrm{~nm})$ NDs. However, a similar treatment was performed on the $50 \mathrm{~nm} \mathrm{ND}$ which has been slightly graphitized via 
annealing at $1000{ }^{\circ} \mathrm{C}$ in vacuum; the detailed process is in elsewhere. ${ }^{14}$ Reannealing of the graphitized ND at $800{ }^{\circ} \mathrm{C}$, a small peak is found at $\sim 2137 \mathrm{~cm}^{-1}$ marked by an arrow (shown in the inset) in Figure $4 \mathrm{a}(\mathrm{ii})$, which is assigned to the

(a)
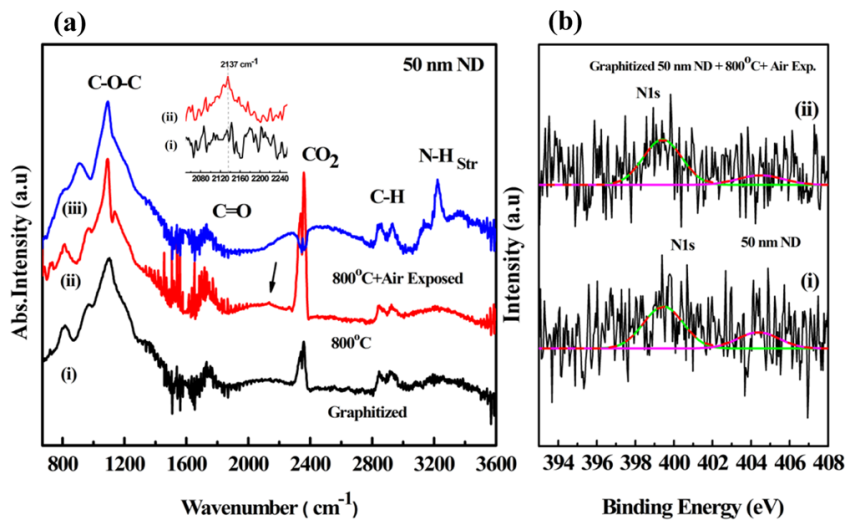

Figure 4. (a) FTIR spectra of $50 \mathrm{~nm} \mathrm{ND}$ graphitized at $1000{ }^{\circ} \mathrm{C}$; (i) only graphitized, (ii) sample (i) reannealed at $800{ }^{\circ} \mathrm{C}$ in vacuum, (iii) sample (ii) exposed in air $24 \mathrm{~h}$, (b) XPS spectra of $50 \mathrm{ND}$; (i) as received/untreated, (ii) graphitized $50 \mathrm{ND}$ reannealed at $800{ }^{\circ} \mathrm{C}$ in vacuum followed by air exposition for $24 \mathrm{~h}$.

isonitrile structure. ${ }^{22}$ In this case, there is no obvious band found for nitrile and primary/secondary amine group during annealing. After air exposition of the reannealed sample for 24 $\mathrm{h}$, a broad band ranging from $3100-3300 \mathrm{~cm}^{-1}$ with a distinct peak at $3228 \mathrm{~cm}^{-1}$ shown in Figure $4 \mathrm{a}$ (iii) is observed. The obtained peak corresponds to the $\mathrm{N}-\mathrm{H}$ stretching vibration, ${ }^{65}$ which indicates the formation of $\mathrm{N}$-formyl derivative structure as found for UDD.

In this case, the reduced intensity of the isonitrile (2137 $\mathrm{cm}^{-1}$ ) compared to the UDD could be the effect of particle size and less surface contaminants $\left(\mathrm{N}, \mathrm{sp}^{2} /\right.$ amorphous carbon). However, this peak is consistent with the effect of hydrogen attack on isonitrile as UDD (Figure 1c(iii) at 750 ${ }^{\circ} \mathrm{C}$ ), which may lead a saturated structure of isonitrile and thereafter hydrolysis during air exposition. Because of the reduced nitrogen content and effect of the particle size, the bond related to the cyano group $(-\mathrm{N}=\mathrm{C}: /-\mathrm{C} \equiv \mathrm{N})$ and their structural change such as saturated one at $\sim 2175 \mathrm{~cm}^{-1}$ might not be very obvious/observable at $800{ }^{\circ} \mathrm{C}$ in IR measurements (similar step is seen at $750{ }^{\circ} \mathrm{C}$ for UDD). The peak of fully saturated structures could be visible at temperatures higher than $800{ }^{\circ} \mathrm{C}$ for larger size ND [similar to UDD at $800{ }^{\circ} \mathrm{C}$ shown Figure 1c(iv)]. The XPS spectrum shown in Figure $4 \mathrm{~b}$ (i) reveals that the as received/untreated surface of larger size ND contains negligible amount of nitrogen. After graphitization followed by reannealing at $800{ }^{\circ} \mathrm{C}$, no considerable change is observed as shown in Figure $4 \mathrm{~b}$ (ii). It is also noted that, because of high surface roughness and almost no $\mathrm{C}=\mathrm{O}$ groups on the graphitized $\mathrm{ND}$, an unavoidable noise signal is always found in the range of water frequency $1500-1800 \mathrm{~cm}^{-1}$ (seen from the IR in Figure 4a) which could overshadow the $\mathrm{N}-\mathrm{H}$ bending vibration. As larger ND contain significantly less/negligible amounts of $\mathrm{sp}^{2}$ or amorphous carbons on the surface compared to smaller sizes, the surface of $50 \mathrm{~nm}$ diamond has been intentionally graphitized by annealing at $1000{ }^{\circ} \mathrm{C}$ in vacuum to create a similar surface structure of UDD. ${ }^{13}$ Using this graphitized sample, the reactions observed for UDD have been analyzed/ repeated. Similar results have been observed for graphitized 50 $\mathrm{nm}$ diamond. It has been mentioned previously that ND contains nitrogen as an impurity because of the irradiation/ production process or $\mathrm{N}-\mathrm{V}$ center creation. The existence of nitrogen in $50 \mathrm{~nm}$ diamond is observed in XPS data. In larger $\mathrm{ND}$, the crystal structure at the near surface contains nitrogen which remains in the graphitic structure as $\mathrm{C}-\mathrm{N}$ bonds during graphitization. This carbon-nitrogen structure is very similar to the surface carbon-nitrogen structure of UDD. Therefore, under similar reaction conditions, they exhibit similar results. Consequently, there has been nitrile and isonitrile structures and primary amine formation on the surface.

\section{CONCLUSIONS}

Detailed analysis of the surface reactive profile, structural transformations, or reconstructions of $\mathrm{ND}$ annealed in the range of pregraphitization stage (Ambient- $800{ }^{\circ} \mathrm{C}$ ) has been demonstrated. It has been shown that low-temperature $(<500$ ${ }^{\circ} \mathrm{C}$ ) annealing UDD in vacuum results in the formation of nitrile and isonitrile $(-\mathrm{N}=\mathrm{C}: /-\mathrm{C} \equiv \mathrm{N})$ structures on the surface of UDD; at higher temperature, their reduction can be possible in the presence of radical hydrogen which leads to amine functionalization. The source of radical hydrogen is a catalytic effect of hydrogen $\left(\mathrm{H}_{2}\right)$ dissociation which also provides $\mathrm{C}-\mathrm{H}$ adsorption on UDD at low temperatures $(\sim 500$ ${ }^{\circ} \mathrm{C}$ ). It has also demonstrated that the hydrolysis of isonitrile is possible which results in $N$-formyl derivative functionalization on the surface of UDD. It is found that all of the phenomena observed on the surface of UDD are driven by the presence of surface $\mathrm{sp}^{2}$ /amorphous carbon which is confirmed by the graphitized larger-size ND. The work provides a new insight into the reactive profile of DND as well as a facile surface modification process which leads to multifunctional surface properties, especially with maximum bioactive moieties, such as $\mathrm{C}-\mathrm{H}, \mathrm{N}-\mathrm{H}$, or $\mathrm{N}-\mathrm{H}_{2}$. It can also be suggested that surface nitrogen (according XPS result of $\mathrm{N} 1 \mathrm{~s}$ after and before the treatment) is bonded in the adjacent graphitic layer of the surface $\mathrm{sp}^{3}$-diamond lattice. Therefore, the obtained groups related to $\mathrm{N}$ ( such as $\mathrm{N}-\mathrm{H}$ and $\mathrm{NH}_{2}$ ) could provide a stable chemical termination with drugs/biomolecules/larger chemicals for further applications.

Beyond the abovementioned properties, the reaction dynamics on the surface of UDD annealed in vacuum could be equally important to the interstellar study. The most common molecules/compounds in the interstellar medium are hydrogen $\left(\mathrm{H}_{2}\right)$, water $\left(\mathrm{H}_{2} \mathrm{O}\right)$, nitrile $(\mathrm{CN})$ /isonitrile $(\mathrm{NC})$, and their unconjugated structures (HCN/HNC). ${ }^{66,67}$ The interaction of those moieties results in the formation of primary/secondary amine $\left(\mathrm{CH}_{3}-\mathrm{NH}_{2} / \mathrm{CH}_{2}-\mathrm{NH}\right)$ and peptide bonding $\left(\mathrm{R}-\mathrm{CONH}_{2} / \mathrm{R}-\mathrm{NH}-\mathrm{CHO}\right)$ and so forth. ${ }^{67-71}$ In addition, the interaction of the cynano-derivative $\left(\mathrm{CH}_{3}-\right.$ $\mathrm{CN} / \mathrm{CH}_{3}-\mathrm{NC}$ ) on the surface of carbonaceous/water medium is studied to reproduce the observed interstellar reactions in laboratory conditions. ${ }^{72}$ Therefore, the studied reaction dynamics on the surface of UDD (one of the presolar grains) could be a model platform in further understanding of interstellar phenomena.

\section{ASSOCIATED CONTENT}

\section{S Supporting Information}

The Supporting Information is available free of charge on the ACS Publications website at DOI: 10.1021/acsomega.9b00776. 
FTIR spectra of UDD annealed at different temperature ranges for $30 \mathrm{~min}$ each step in vacuum and photograph and datasheet of the samples used (PDF)

\section{AUTHOR INFORMATION}

\section{Corresponding Author}

*E-mail: clcheng@gms.ndhu.edu.tw.

\section{ORCID $\odot$}

Laia Gines: 0000-0001-9980-054X

Soumen Mandal: 0000-0001-8912-1439

Chia-Liang Cheng: 0000-0001-9572-4308

\section{Notes}

The authors declare no competing financial interest.

\section{ACKNOWLEDGMENTS}

The authors are grateful for the financial support of this research by the Ministry of Science and Technology (MOST) of Taiwan for a Taiwan-UK exchange program under grant no. MOST-103-2911-I-259-501. Cardiff University would like to thank the Royal Society International Exchanges Scheme (IE131713) and EU FP7 FET Open "Wavelength tunable Advanced Single Photon Sources”.

\section{REFERENCES}

(1) Mochalin, V. N.; Shenderova, O.; Ho, D.; Gogotsi, Y. The properties and applications of nanodiamonds. Nat. Nanotechnol. 2012, $7,11-23$.

(2) Perevedentseva, E.; Lin, Y.-C.; Jani, M.; Cheng, C.-L. Biomedical applications of nanodiamonds in imaging and therapy. Nanomedicine 2013, 8, 2041-2060.

(3) Krueger, A.; Lang, D. Functionality is Key: Recent Progress in the Surface Modification of Nanodiamond. Adv. Funct. Mater. 2012, 22, 890-906.

(4) Chiganova, G. A. Aggregation of Particles in Ultradispersed Diamond Hydrosols. Colloid J. 2000, 62, 238-243.

(5) Krüger, A.; Kataoka, F.; Ozawa, M.; Fujino, T.; Suzuki, Y.; Aleksenskii, A. E.; Vul', A. Y.; Ōsawa, E. Unusually tight aggregation in detonation nanodiamond: Identification and disintegration. Carbon 2005, 43, 1722-1730.

(6) Krüger, A.; Liang, Y.; Jarre, G.; Stegk, J. Surface functionalisation of detonation diamond suitable for biological applications. J. Mater. Chem. 2006, 16, 2322-2328.

(7) Krueger, A. Chapter 8-Current issues and challenges in surface chemistry of nanodiamonds A2-Arnault, Jean-Charles. In Nanodiamonds; Elsevier, 2017; pp 183-242.

(8) Ahmed, A.-I.; Mandal, S.; Gines, L.; Williams, O. A.; Cheng, C.L. Low temperature catalytic reactivity of nanodiamond in molecular hydrogen. Carbon 2016, 110, 438-442.

(9) Lin, Y.; Sun, X.; Su, D. S.; Centi, G.; Perathoner, S. Catalysis by hybrid $\mathrm{sp}^{2} / \mathrm{sp}^{3}$ nanodiamonds and their role in the design of advanced nanocarbon materials. Chem. Soc. Rev. 2018, 47, 8438-8473.

(10) Williams, O. A.; Hees, J.; Dieker, C.; Jäger, W.; Kirste, L.; Nebel, C. E. Size-dependent reactivity of diamond nanoparticles. ACS Nano 2010, 4, 4824-4830.

(11) Srimani, D.; Feller, M.; Ben-David, Y.; Milstein, D. Catalytic coupling of nitriles with amines to selectively form imines under mild hydrogen pressure. Chem. Commun. 2012, 48, 11853-11855.

(12) Bagal, D. B.; Bhanage, B. M. Recent Advances in Transition Metal-Catalyzed Hydrogenation of Nitriles. Adv. Synth. Catal. 2015, 357, 883-900.

(13) Chase, P. A.; Welch, G. C.; Jurca, T.; Stephan, D. W. MetalFree Catalytic Hydrogenation. Angew. Chem., Int. Ed. 2007, 46, 80508053.
(14) Ginés, L.; Mandal, S.; Ashek-I-Ahmed; Cheng, C.-L.; Sow, M.; Williams, O. A. Positive zeta potential of nanodiamonds. Nanoscale 2017, 9, 12549-12555.

(15) Jarre, G.; Heyer, S.; Memmel, E.; Meinhardt, T.; Krueger, A. Synthesis of nanodiamond derivatives carrying amino functions and quantification by a modified Kaiser test. Beilstein J. Org. Chem. 2014, 10, 2729-2737.

(16) Hopper, A. P.; Dugan, J. M.; Gill, A. A.; Fox, O. J. L.; May, P. W.; Haycock, J. W.; Claeyssens, F. Amine functionalized nanodiamond promotes cellular adhesion, proliferation and neurite outgrowth. Biomed. Mater. 2014, 9, 045009.

(17) Mochalin, V. N.; Neitzel, I.; Etzold, B. J. M.; Peterson, A.; Palmese, G.; Gogotsi, Y. Covalent Incorporation of Aminated Nanodiamond into an Epoxy Polymer Network. ACS Nano 2011, 5, 7494-7502.

(18) Wenxuan, W.; Wancong, B.; Ying, Y. In Incorporation of nanodiamond into an epoxy polymer network with high thermal conductivity for electrical insulations. 2016 IEEE International Conference on Dielectrics (ICD), 3-7 July 2016; 2016; pp 868-871.

(19) Aris, A.; Shojaei, A.; Bagheri, R. Cure Kinetics of Nanodiamond-Filled Epoxy Resin: Influence of Nanodiamond Surface Functionality. Ind. Eng. Chem. Res. 2015, 54, 8954-8962.

(20) Sun, T.; Fan, H.; Zhuo, Q.; Liu, X.; Wu, Z. Covalent incorporation of aminated carbon nanotubes into epoxy resin network. High Perform. Polym. 2014, 26, 892-899.

(21) Saini, G.; Jensen, D. S.; Wiest, L. A.; Vail, M. A.; Dadson, A.; Lee, M. L.; Shutthanandan, V.; Linford, M. R. Core-Shell Diamond as a Support for Solid-Phase Extraction and High-Performance Liquid Chromatography. Anal. Chem. 2010, 82, 4448-4456.

(22) Socrates, G. Infrared and Raman Characteristic Group Frequencies: Tables and Charts, 3rd ed.; John Wiley \& Sons, Ltd.: Chichester, U.K., 2004; p 366.

(23) Cheng, C.-L.; Chen, C.-F.; Shaio, W.-C.; Tsai, D.-S.; Chen, K.$\mathrm{H}$. The $\mathrm{CH}$ stretching features on diamonds of different origins. Diamond Relat. Mater. 2005, 14, 1455-1462.

(24) Maj, M.; Ahn, C.; Błasiak, B.; Kwak, K.; Han, H.; Cho, M. Isonitrile as an Ultrasensitive Infrared Reporter of Hydrogen-Bonding Structure and Dynamics. J. Phys. Chem. B 2016, 120, 10167-10180.

(25) Rodil, S. E.; Ferrari, A. C.; Robertson, J.; Muhl, S. Infrared spectra of carbon nitride films. Thin Solid Films 2002, 420-421, 122131.

(26) Shenderova, O. A.; Vlasov, I. I.; Turner, S.; Van Tendeloo, G.; Orlinskii, S. B.; Shiryaev, A. A.; Khomich, A. A.; Sulyanov, S. N.; Jelezko, F.; Wrachtrup, J. Nitrogen Control in Nanodiamond Produced by Detonation Shock-Wave-Assisted Synthesis. J. Phys. Chem. C 2011, 115, 14014-14024.

(27) Kaufman, J. H.; Metin, S.; Saperstein, D. D. Symmetry breaking in nitrogen-doped amorphous carbon: Infrared observation of the Raman-activeGandDbands. Phys. Rev. B: Condens. Matter Mater. Phys. 1989, 39, 13053-13060.

(28) Ramozzi, R.; Chéron, N.; Braïda, B.; Hiberty, P. C.; FleuratLessard, P. A valence bond view of isocyanides' electronic structure. New J. Chem. 2012, 36, 1137-1140.

(29) Sung, K. Substituent Effects on Stability and Isomerization Energies of Isocyanides and Nitriles. J. Org. Chem. 1999, 64, 89848989.

(30) Wang, D.; Qian, X.; Zhang, Q. The isonitrile-nitrile isomerization: kinetic parameters, reaction mechanism and relative photoionization cross-section of the HOMO. A HeI photoelectron spectroscopy study. Chem. Phys. Lett. 1997, 266, 560-567.

(31) Meier, M.; Mueller, B.; Ruechardt, C. The isonitrile-nitrile rearrangement. A reaction without a structure-reactivity relationship. J. Org. Chem. 1987, 52, 648-652.

(32) Berg, R. F. Hydrogen traps in the outgassing model of a stainless steel vacuum chamber. J. Vac. Sci. Technol., A 2014, 32, 031604.

(33) Calder, R.; Lewin, G. Reduction of stainless-steel outgassing in ultra-high vacuum. Br. J. Appl. Phys. 1967, 18, 1459. 
(34) Wang, H.; Eremets, M. I.; Troyan, I.; Liu, H.; Ma, Y.; Vereecken, L. Nitrogen Backbone Oligomers. Sci. Rep. 2015, 5, 13239.

(35) Mavroyannis, C.; Winkler, C. A. THE REACTION OF NITROGEN ATOMS WITH HYDROGEN ATOMS. Can. J. Chem. 1962, 40, 240-245.

(36) Li, C.-Z.; Tan, L. L. Formation of NOx and SOx precursors during the pyrolysis of coal and biomass. Part III. Further discussion on the formation of $\mathrm{HCN}$ and $\mathrm{NH} 3$ during pyrolysis. Fuel 2000, 79, 1899-1906.

(37) Adamson, A.; Kaljurand, I.; Guillemin, J.-C.; Burk, P. Relative stability and proton transfer reactions of unsaturated isocyanides and cyanides. J. Phys. Org. Chem. 2016, 29, 452-459.

(38) Bouchoux, G.; Eckert-Maksic, M. Gas phase basicities of polyfunctional molecules. Part 5: Non-aromatic sp2 nitrogen containing compounds. Mass Spectrom. Rev. 2018, 37, 139-170.

(39) Zhang, H.; Jiang, X.; Wu, W.; Mo, Y. Electron conjugation versus $\pi-\pi$ repulsion in substituted benzenes: why the carbon-nitrogen bond in nitrobenzene is longer than in aniline. Phys. Chem. Chem. Phys. 2016, 18, 11821-11828.

(40) Blum, P. M.; Roberts, B. P. An electron spin resonance study of radical addition to alkyl isocyanides. J. Chem. Soc., Perkin Trans. 2 1978, 1313-1319.

(41) Zhang, B.; Studer, A. Recent advances in the synthesis of nitrogen heterocycles via radical cascade reactions using isonitriles as radical acceptors. Chem. Soc. Rev. 2015, 44, 3505-3521.

(42) Trevitt, A. J.; Goulay, F. Insights into gas-phase reaction mechanisms of small carbon radicals using isomer-resolved product detection. Phys. Chem. Chem. Phys. 2016, 18, 5867-5882.

(43) Mo, Y.; Lin, Z.; Wu, W.; Zhang, Q. Delocalization in Allyl Cation, Radical, and Anion. J. Phys. Chem. 1996, 100, 6469-6474.

(44) Perevedentseva, E.; Cheng, C.-Y.; Chung, P.-H.; Tu, J.-S.; Hsieh, Y.-H.; Cheng, C.-L. The interaction of the protein lysozyme with bacteria E. coli observed using nanodiamond labelling. Nanotechnology 2007, 18, 315102.

(45) Silva, S. R. P.; Robertson, J.; Amaratunga, G. A. J.; Rafferty, B.; Brown, L. M.; Schwan, J.; Franceschini, D. F.; Mariotto, G. Nitrogen modification of hydrogenated amorphous carbon films. J. Appl. Phys. 1997, 81, 2626-2634.

(46) Lim, Y. Y.; Stein, A. R. Acid-catalyzed Solvolysis of Isonitriles. I. Can. J. Chem. 1971, 49, 2455-2459.

(47) Kheirjou, S.; Fattahi, A.; Hashemi, M. M. The intramolecular cation- $\pi$ interaction of some aryl amines and its drastic influence on the basicity of them: AIM and NBO analysis. Comput. Theor. Chem. 2014, 1036, 51-60.

(48) Bruckner, R. Organic Mechanisms; Reactions, Stereochemistry and Synthesis, 1 ed.; Springer-Verlag Berlin Heidelberg, 2010.

(49) Zhao, F.; Vrajitoarea, A.; Jiang, Q.; Han, X.; Chaudhary, A.; Welch, J. O.; Jackman, R. B. Graphene-Nanodiamond Heterostructures and their application to High Current Devices. Sci. Rep. 2015, 5, 13771.

(50) Gouzman, I.; Brener, R.; Hoffman, A. Nitridation of diamond and graphite surfaces by low energy $\mathrm{N}_{2}{ }^{+}$ion irradiation. Surf. Sci. 1995, 331-333, 283-288.

(51) Susi, T.; Pichler, T.; Ayala, P. X-ray photoelectron spectroscopy of graphitic carbon nanomaterials doped with heteroatoms. Beilstein J. Nanotechnol. 2015, 6, 177-192.

(52) Ando, T.; Yamamoto, K.; Ishii, M.; Kamo, M.; Sato, Y. Vapourphase oxidation of diamond surfaces in $\mathrm{O} 2$ studied by diffuse reflectance Fourier-transform infrared and temperture-programmed desorption spectroscopy. J. Chem. Soc., Faraday Trans. 1993, 89, 3635-3640.

(53) Yeganeh, M.; Coxon, P. R.; Brieva, A. C.; Dhanak, V. R.; Šiller, L.; Butenko, Y. V. Atomic hydrogen treatment of nanodiamond powder studied with photoemission spectroscopy. Phys. Rev. B: Condens. Matter Mater. Phys. 2007, 75, 155404.

(54) McCann, R.; Roy, S. S.; Papakonstantinou, P.; McLaughlin, J. A.; Ray, S. C. Spectroscopic analysis of a-C and a-CNx films prepared by ultrafast high repetition rate pulsed laser deposition. J. Appl. Phys. 2005, 97, 073522.
(55) Jansen, R. J. J.; van Bekkum, H. XPS of nitrogen-containing functional groups on activated carbon. Carbon 1995, 33, 1021-1027. (56) Yang, G.; Chen, H.; Qin, H.; Feng, Y. Amination of activated carbon for enhancing phenol adsorption: Effect of nitrogen-containing functional groups. Appl. Surf. Sci. 2014, 293, 299-305.

(57) Zhao, X.; Zhang, S.; Bai, C.; Li, B.; Li, Y.; Wang, L.; Wen, R.; Zhang, M.; Ma, L.; Li, S. Nano-diamond particles functionalized with single/double-arm amide-thiourea ligands for adsorption of metal ions. J. Colloid Interface Sci. 2016, 469, 109-119.

(58) Jeong, S. H.; Lim, D.; Kim, K.; Kang, E.; Lim, S.; Ricci, J.; Sung, S.; Kwon, M. Comprehensive evaluation of carboxylated nanodiamond as a topical drug delivery system. Int. J. Nanomed. 2016, 11, 2381-2395

(59) Ferrari, A. C.; Robertson, J. Raman spectroscopy of amorphous, nanostructured, diamond-like carbon, and nanodiamond. Philos. Trans. R. Soc., A 2004, 362, 2477.

(60) Korepanov, V. I.; Hamaguchi, H.-o.; Osawa, E.; Ermolenkov, V.; Lednev, I. K.; Etzold, B. J. M.; Levinson, O.; Zousman, B.; Epperla, C. P.; Chang, H.-C. Carbon structure in nanodiamonds elucidated from Raman spectroscopy. Carbon 2017, 121, 322-329.

(61) Osswald, S.; Mochalin, V. N.; Havel, M.; Yushin, G.; Gogotsi, Y. Phonon confinement effects in the Raman spectrum of nanodiamond. Phys. Rev. B: Condens. Matter Mater. Phys. 2009, 80, 075419.

(62) Mochalin, V.; Osswald, S.; Gogotsi, Y. Contribution of Functional Groups to the Raman Spectrum of Nanodiamond Powders. Chem. Mater. 2009, 21, 273-279.

(63) Osswald, S.; Yushin, G.; Mochalin, V.; Kucheyev, S. O.; Gogotsi, Y. Control of $\mathrm{sp}^{2} / \mathrm{sp}^{3}$ Carbon Ratio and Surface Chemistry of Nanodiamond Powders by Selective Oxidation in Air. J. Am. Chem. Soc. 2006, 128, 11635-11642.

(64) Kuznetsov, V. L.; Zilberberg, I. L.; Butenko, Y. V.; Chuvilin, A. L.; Segall, B. Theoretical study of the formation of closed curved graphite-like structures during annealing of diamond surface. J. Appl. Phys. 1999, 86, 863-870.

(65) Heacock, R. A.; Marion, L. The infrared spectra of secondary amines and their salts. Can. J. Chem. 1956, 34, 1782-1795.

(66) Chadha, M. S. Radicals, Ions and Molecules in Chemical Evolution. In Exobiology: Matter, Energy, and Information in the Origin and Evolution of Life in the Universe: Proceedings of the Fifth Trieste Conference on Chemical Evolution: An Abdus Salam Memorial Trieste, Italy, 22-26 September 1997; Chela-Flores, J.; Raulin, F., Eds.; Springer: Netherlands: Dordrecht, 1998; pp 107-112.

(67) Saladino, R.; Crestini, C.; Pino, S.; Costanzo, G.; Di Mauro, E. Formamide and the origin of life. Phys. Life Rev. 2012, 9, 84-104.

(68) Halfen, D. T.; Ilyushin, V. V.; Ziurys, L. M. Insights into Surface Hydrogenation in the Interstellar Medium: Observations of Methanimine and Methyl Amine in Sgr B2(N). Astrophys. J. 2013, $767,66$.

(69) Basiuk, V. A. Formation of Amino Acid Precursors in the Interstellar Medium. A DFT Study of Some Gas-Phase Reactions Starting with Methylenimine. J. Phys. Chem. A 2001, 105, 4252-4258.

(70) Halfen, D. T.; Ilyushin, V.; Ziurys, L. M. Formation of Peptide Bonds in Space: A Comprehensive Study of Formamide and Acetamide in Sgr B2(N). Astrophys. J. 2011, 743, 60.

(71) Belloche, A.; Meshcheryakov, A. A.; Garrod, R. T.; Ilyushin, V. V.; Alekseev, E. A.; Motiyenko, R. A.; Margulès, L.; Müller, H. S. P.; Menten, K. M. Rotational spectroscopy, tentative interstellar detection, and chemical modeling of $\mathrm{N}$-methylformamide. Astron. Astrophys. 2017, 601, A49.

(72) Bertin, M.; Doronin, M.; Michaut, X.; Philippe, L.; Markovits, A.; Fillion, J. H.; Pauzat, F.; Ellinger, Y.; Guillemin, J.-C. Nitrile versus isonitrile adsorption at interstellar grain surfaces. Astron. Astrophys. 2017, 608, A50. 